\title{
A STUDY ON THE JOINING TECHNOLOGY OF COPPER-ALUMINIUM COMPOSITE HEAT-DISSIPATING COMPONENTS
}

\author{
*BIAN Yan-fei, SHI Jian-zhou, XIE Ming-jun, and CAI Meng
}

The $54^{\text {th }}$ Research Institute of China Electronics Technology Group Corporation, Shijiazhuang 050081, China

\begin{abstract}
Copper-aluminium composite heat dissipation components have both the high thermal conductivity of copper and the low density of aluminium. Copper and aluminium are dissimilar materials as they have significant differences in physical and chemical properties, and hence it is not easy to weld them together. In this paper, the joining of copper to aluminium is studied by using the ultrasonic brazing technique. The results show that the copper and aluminium can be connected by ultrasonic brazing, and it is found that the bonding of the copper side interface is the weak link of the entire joint, but the joint strength can still reach $95 \mathrm{MPa}$.
\end{abstract}

Keywords: Copper aluminium composite structure, Radiator, Heat exchange, Heat sink, Ultrasonic brazing.

\section{Introduction}

With the development of electronic devices towards high frequency and integration, the rapid increase of heat production will inevitably bring urgent demand for heat dissipation [1,2]. Aluminum does not conduct heat fast enough to transfer heat from the inside to the air contact surface for heat exchange, which will cause heat accumulation [3]. With the improvement of heat dissipation equipment performance, the demand for copper-aluminium composite radiators will increase. The composite structure composed of copper and aluminium [4] can reduce the weight and cost of the components and exert their respective performance advantages. Therefore, this kind of composite structure has a wide application prospect in electronics, aerospace, refrigeration, chemical and other industries.

Due to the significant difference in performance between copper and aluminium, it is not easy to achieve a good joining for copper-aluminium composites using conventional welding processes. At present, the copper-aluminium composite structure is formed by means of explosion welding [5 \& 6] and high vacuum extrusion[7]. In recent years, with the emergence of high-power and highly integrated liquid cooling structures [8], higher requirements for heat dissipation are put forward. The split structure can ensure good machining accuracy and reduce the difficulty of material forming, but it increases the difficulty of welding. At present, low-temperature brazing is widely used in a large-area copper-aluminium composite structure, but the strength and rigidity are low, and it is not easy to ensure the tightness of the water channel.

The ultrasonic brazing method[9] is suitable for dissimilar welding materials such as aluminium and copper. Because of its unique welding method and flexibility of operation, ultrasonic brazing can complete the precision welding of unique and complex structures. The brazing method has low cost and is suitable for joining precision, miniature, complex and multi-seam workpieces. Due to the low melting point filler metal is used to fill the joint gap, the brazing temperature is generally far lower than the melting point of the base metal, the residual stress after welding is small, and the growth of intermetallic compound at the joint interface can be effectively inhibited, which is more suitable for $\mathrm{Cu} / \mathrm{Al}$ dissimilar metal bonding.

\section{Experimental}

5A06 aluminium alloy and pure industrial copper (red copper) were used as raw materials, and $\mathrm{Zn}$ based solder was used as filler metal. In this study, ultrasonic brazing was used to realize the brazing joining under atmospheric conditions without the application of flux. The cavitation effect and acoustic flow effect of ultrasonic in liquid were used to remove the oxide film and control the uniform distribution of elements in the solder metal. Brazing process: heating temperature is $400 \sim 450^{\circ} \mathrm{C}$, ultrasonic action time is $10 \sim 30 \mathrm{~s}$, the ultrasonic amplitude is $5 \sim 18 \mu \mathrm{m}$. 
The mosaic structure is used to complete the welding of the experimental parts, which can fully reflect some advantages of the welding method. The test piece is shown in Fig 1. From the overall macro image, it can be seen that there are no macro defects in the upper surface of the weld, the side weld and the bottom weld, the filling rate can reach $100 \%$, no inclusions or gas, and the welding quality is good, as shown in Fig 2.

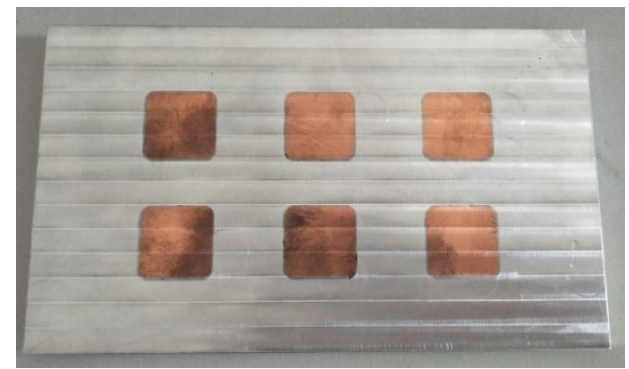

Fig. 1 Top view of welding sample

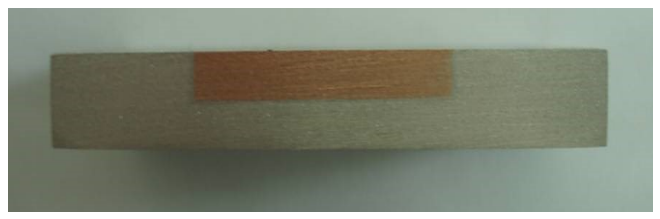

Fig. 2 Front view of welding sample section

The microstructure of the joint was analyzed by optical microscope (OLYMPUS-PMG3) and scanning electron microscope (Quanta200F). The strength of the joint was tested using an electronic universal material tester (Instron-5569). The hardness of the joint was tested using a hardness tester (Bareiss).

\section{Results and Discussion}

A metallographic specimen was prepared by randomly intercepting a joint section from the welding specimen and then performing optical microstructure observation after polishing. It was found that there were almost no defects in the entire joint weld, and only a few areas were distributed with tiny pores. The oxide film at the interface on both sides was almost completely removed, and a good bond was formed. By observing the copper side interface, it is found that the liquid solder has formed a certain degree of corrosion on the copper base metal during the ultrasonic brazing process, and the corrosion size is about $10-30 \mu \mathrm{m}$. For the weld metal, it can be seen from the color difference that a microstructure with a light gray structure as the matrix and a darker color granular structure is formed, but it is difficult to obtain detailed information on the structure and morphology of the structure. Therefore, the joint is treated with corrosion treatment based on different elements or different corrosion resistance properties. Thus, the morphology of the microstructure in the weld can be highlighted.

The sample was treated by the chemical etching method. The polished sample was washed with water, and the residual dirt on the surface to be corroded was wiped off with alcohol. Then the surface to be corroded was immersed in the mixed corrosive agent (10vol.\% nitric acid, the rest of alcohol) for several seconds. Bubbles were observed on the corroded surface. When the polished surface was bright, the metal luster gradually lost (weld area). The sample has to be taken out immediately and rinse it with water, rinse it with alcohol, finally absorb it with filter paper and blow it to dry with compressed air at $60 \sim 90^{\circ} \mathrm{C}$. That is, the corrosion is complete. If the single etching effect is not good, it can be re-polished and then re-etched.

The corrosion joint was observed in a macroscopic way, and the metallurgical combination was formed on both sides of the interface. It was found that inconsistent corrosion behaviour was formed in some areas of the copper side interface. There is no significant difference in the joint structure in all areas of the whole welding specimen. Through the observation of the welding area of the joint, it is found that the whole weld area is mainly composed of four structures, namely, gray irregular dendrite A, dark black matrix B, light gray block structure $\mathrm{C}$ and light gray long strip structure D, as shown in Fig 3. Preliminary judgments can be made from the color, shape and corrosion resistance of the elements. $\mathrm{A}$ is an aluminium-rich phase, $\mathrm{B}$ is a $\mathrm{Zn}$-rich phase, and $\mathrm{C}$ and $\mathrm{D}$ are $\mathrm{Cu}-\mathrm{Al}$ compounds, and they may be the same compound. The whole welding seam presents this structure characteristic, which indicates that the welding seam microstructure presents the characteristic of homogenization.

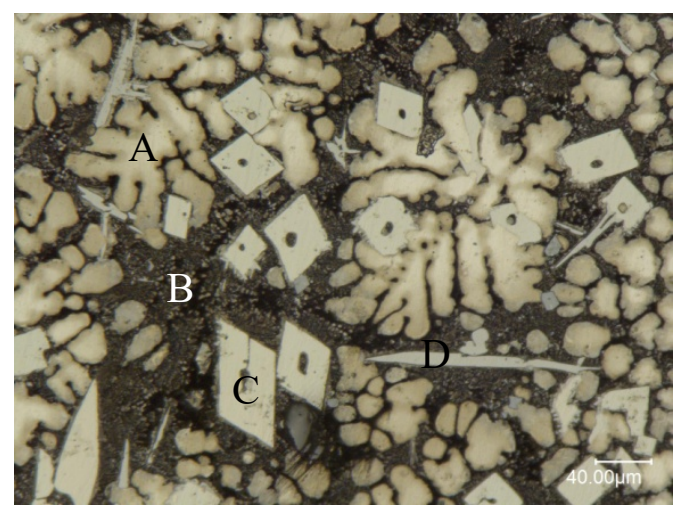

Fig. 3 Metallographic structure of welded joint after corrosion 
The interface is a critical area of the entire joint. At the interface of the aluminium side, the oxide film on the surface of the aluminium alloy base metal has been completely removed, and the liquid solder alloy dissolves the aluminium alloy base metal. There are also four structures similar to the weld seam (A, B, $\mathrm{C}, \mathrm{D})$. Almost all of the structures at the interface are class A, and no coarse structure is found at the interface. At the copper side interface, the solder and copper base metal form a good combination, and there are four similar structures, and there is no coarse structure.

EDS analyzed the microstructure composition of the weld, and the specific composition was shown in Table 1. The matrix B in the weld is $\mathrm{Zn}-\mathrm{Al}-\mathrm{Cu}-\mathrm{Mg}$ quaternary eutectic structure, showing a typical eutectic structure pattern. Dendritic A is $\alpha-\mathrm{Al}$, which indicates that the solder dissolves the base metal to a certain extent during the welding process, resulting in the increase of aluminium content in the weld, and precipitates out and grows in the form of dendritic. Both $\mathrm{C}$ and $\mathrm{D}$ are $\mathrm{CuAl}_{2}$ compounds, but different crosssections show different shape characteristics.

\section{Table 1 Composition of welding joints}

\begin{tabular}{ccccccc}
\hline $\begin{array}{c}\text { Posi } \\
\text { tion }\end{array}$ & Zn & Al & $\mathbf{C u}$ & $\mathbf{M g}$ & Si & $\begin{array}{c}\text { Organi } \\
\text { zation }\end{array}$ \\
\hline $\mathrm{A}$ & 43.28 & 52.20 & 3.92 & 0.38 & 0.23 & $\alpha-\mathrm{Al}$ \\
$\mathrm{B}$ & 60.30 & 19.10 & 8.44 & 11.7 & 0.37 & $\mathrm{Zn}-\mathrm{Al}-$ \\
$\mathrm{C}$ & 2.45 & 67.37 & 29.65 & 0 & 0.52 & $\mathrm{CuAl}$ \\
$\mathrm{D}$ & 4.18 & 68.05 & 27.21 & 0.17 & 0.39 & $\mathrm{CuAl}_{2}$ \\
\hline
\end{tabular}

A good interfacial joining is formed at the aluminium alloy side, and there is a transition layer at the interface, as shown in Fig 4. The line scan analysis of the interface shows that the interlayer is caused by the diffusion of $\mathrm{Zn}$ into the aluminium alloy as shown in Fig 5. The interlayer is $\alpha-\mathrm{Al}$ with solid solution of $\mathrm{Zn}$, but its $\mathrm{Zn}$ content is less than that of the $\alpha-\mathrm{Al}$ phase in the weld. The $\mathrm{CuAl}_{2}$ compound also exists at the local interface.

The formation mechanism of brazing joint: Under the ultrasonic action, the cavitation effect in the liquid solder alloy breaks the oxide film on the surface of the base material, and an appropriate amount of dissolution of the base material into the base material solder occurs. The acoustic flow effect of ultrasonic makes the dissolved elements diffuse rapidly, and the weld composition is uniform. During the cooling process, $\mathrm{CuAl}_{2}$ compound and $\alpha-\mathrm{Al}$ phase solid solution are randomly generated in the weld, thus forming a relatively uniform weld microstructure similar to the structural characteristics of composite materials.
Therefore, there is no single coarse structure formed due to element segregation at the interface, especially copper side interface, and there is no continuous coarse $\mathrm{CuAl}_{2}$ and $\mathrm{Al}_{4.2} \mathrm{Cu}_{3.2} \mathrm{Zn}_{0.7}$ compounds.

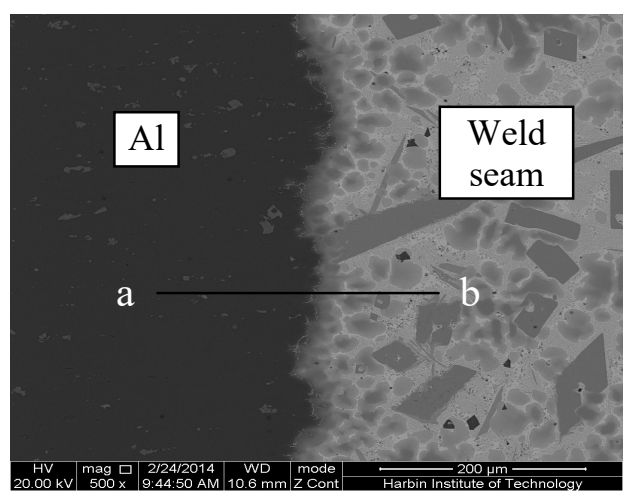

Fig. 4 Interface structure of the aluminium side of the joint

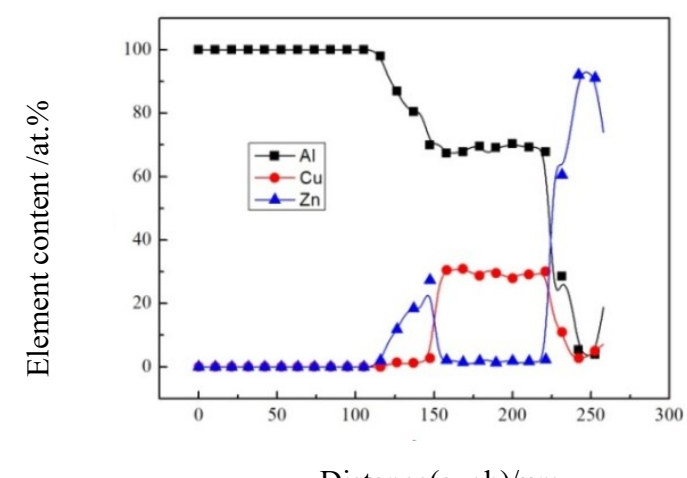

Fig. 5 The results of line scanning energy spectrum analysis of aluminium side interface (Line ab in Fig 4)

Some samples were taken from the welding samples for performance test, mainly to investigate the shear performance of the joint. The size of the performance samples: length, width and height are $5 \mathrm{~mm}, 5 \mathrm{~mm}$, and $10 \mathrm{~mm}$, respectively. In order to obtain stable joint values, six samples were randomly intercepted. From the test results (Table 2), it can be found that the shear strength of the joint is relatively stable, and the average shear strength can reach about $95 \mathrm{MPa}$.

Table 2 Shear strength of joint

\begin{tabular}{ccccccc}
\hline No. & 1 & 2 & 3 & 4 & 5 & 6 \\
\hline $\begin{array}{c}\text { Strength } \\
\text { /MPa }\end{array}$ & 98.11 & 89.37 & 94.82 & 91.08 & 97.46 & 100.19 \\
\hline
\end{tabular}


Generally speaking, for the same material specimen, the shear strength is lower than the tensile strength. For example, the shear strength of steel is $0.6 \sim$ 0.8 times the tensile strength, so the tensile strength of the joint obtained by the ultrasonic brazing method is still higher than the shear strength value.

The use of ultrasonic brazing to connect the copper/aluminium joint has higher strength and good process stability, which is particularly important for improving the stability of the copper-aluminium composite structure. In addition, there is no corrosion problem caused by residual flux, which is very beneficial to the stability and prolonging the service time of the joint.

The effect of the interfacial compound on the strength of the joint is very important. For this reason, the hardness analysis was carried out on the structure near the copper side interface, as shown in Fig.6. The hardness data is shown in Table 3. It is difficult to obtain the hardness value of compounds near the interface, but it can be known that $\mathrm{Cu}-\mathrm{Al}$ compounds belong to brittle and hard structures from the hardness value of bulk compounds. Because the general hard and brittle compounds are sensitive to cracks due to their poor plasticity and toughness, the existence of the interface hard and brittle compounds must have an impact on the performance of the joint. For $\mathrm{Cu}-\mathrm{Al}$ elements, it is difficult to avoid the production of interface compounds, and reasonable control of the thickness and type of interfacial compounds will help to improve the interfacial bonding strength.

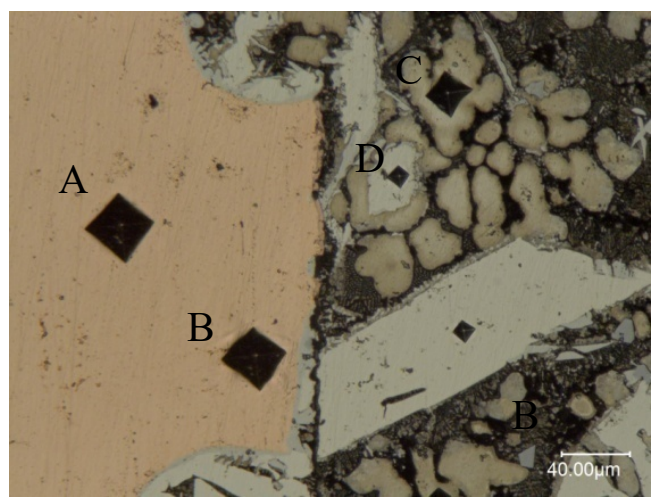

Fig. 6 Test point of structure hardness near copper side interface

Table 3 Hardness distribution of the microstructure near the copper side interface

\begin{tabular}{ccccc}
\hline Position & $\mathrm{A}$ & $\mathrm{B}$ & $\mathrm{C}$ & $\mathrm{D}$ \\
\hline Hardness/HV & 58 & 60 & 203 & 502 \\
Organization & $\mathrm{Cu}$ & $\mathrm{Cu}$ & $\alpha-\mathrm{Al}$ & $\mathrm{CuAl}_{2}$ \\
\hline
\end{tabular}

\section{Conclusions}

The copper/aluminium joining can be realized by the ultrasonic brazing method, and the bonding of the copper side interface is still the weak link of the entire joint. However, compared with the copper/aluminium joint strength reported in the literature, the joint strength of this method is higher (95MPa). It was found that high-strength joints can be produced by introducing ultrasonic in the brazing process. The cavitation effect helps to realize the removal of the surface oxidation film on the parent material. However, the sound flow effect helps to homogenize the components in the liquid weld. It makes the final weld a uniformly distributed organization structure and suitable interface reaction products.

\section{References}

1. Xinyu Fan, Hongjiang Cui, Yongsui Xu (2020), IGBT Heat Dissipation Design and Optimization, Journal of Physics: Conference Series, vol.1635, 012024.

2. Yaniv Cohen, Siva K. Reddy, Assaf Ya'akobovitz (2021), Heat dissipation in graphene foams, Nano Research, vol.14, no. 3, 829-833.

3. Han Shuang, Yang Lixin, Tian Zihao, Yuan Xiaofei, Lu Hongyan (2020), Research on a Simplified Model of an Aluminum Vapor Chamber in a Heat Dissipation System, Entropy, vol.22, no.1,35.

4. Sameer Hashim Ameen, Deyaa Mohammed Noori Mahmood, Younus Fahad Breesam (2019), Enhancement of Heat Dissipation from Computer Processor using Layer Copper-Aluminum Composite Materials, Journal of Engineering and Applied Sciences, vol.14, no.5,9048-9055.

5. Chen D.-G, Yao Y, Deng Y, Su L.-F (2019), Effects of Covering Thickness of Explosives on Explosive Welding, Chinese Journal of Explosives and Propellants, vol.42, no.1,52-57.

6. Tingting Zhang, Wenxian Wang, Zhifeng Yan, Jie Zhang (2021), Interfacial Morphology and Bonding Mechanism of Explosive Weld Joints, Chinese Journal of Mechanical Engineering, vol.34, no.1,1-12.

7. Ma YQ, Qi LH, Zhou JM, Zhang T,Li HJ (2017), Effects of Process Parameters on Fabrication of 2D-C/Al Composite Parts by Liquid-Solid Extrusion Following the Vacuum Infiltration Technique, Metallurgical \& Materials Transactions. Part B, vol.48, no.1,582-590.

8. Siqi Chen, Nengsheng Bao, Liang Gao, Xiongbin Peng, Akhil Garg (2020), An experimental investigation of liquid cooling scheduling for a battery module, International Journal of Energy Research, vol.44, no.4,3020-3032.

9. Dai Jun, Yu Banglong, Yang Li,Zhang Yaocheng, Liu Zili, Liu Po (2020). Microstructure and Mechanical Properties of Ultrasonically Assisted Brazing of Dissimilar $\mathrm{Cu}-\mathrm{Al}$ Alloys, Science of Advanced Materials, vol.12, no.5,733739 